Gut and Liver, Vol. 11, No. 5, September 2017, pp. 721-727

\title{
Direct Acting Antiviral Agents in Korean Patients with Chronic Hepatitis C and Hemophilia Who Are Treatment-Naïve or Treatment-Experienced
}

\author{
Hyun Woong Lee ${ }^{1}$, Ki Young Yoo ${ }^{2}$, Joung Won Won ${ }^{1}$, and Hyung Joon $\mathrm{Kim}^{1}$ \\ ${ }^{1}$ Department of Internal Medicine, Chung-Ang University College of Medicine, and ${ }^{2}$ Department of Pediatrics, Korea Hemophilia Foundation \\ Hospital, Seoul, Korea
}

Background/Aims: Chronic hepatitis $\mathrm{C}(\mathrm{CHC})$ is a major comorbidity in patients with hemophilia. Methods: Patients $(n=30)$ were enrolled between September 2015 and April 2016. Twenty-six patients were genotype 1 (1b, $n=21 ; 1 a$, $n=5$ ) and four patients were genotype $2 a / 2 b$. Among 21 patients with genotype $1 \mathrm{~b}, \mathrm{Y93H}$ resistance-associated variants (RAVs) were detected in three patients (14.3\%). We evaluated sustained virologic response (SVRs) at 12 weeks, as well as relapse and safety. Results: Five patients with genotype 1a and three patients with genotype 1b (RAV positive) received ledipasvir/sofosbuvir for 12 weeks. SVR12 rate was $100 \%$ (8/8). Eleven patients with genotype $1 \mathrm{~b}$ were treatment-naïve and received daclatasvir plus asunaprevir for 24 weeks. SVR12 rate was 91\% (10/11). One patient experienced viral breakthrough without RAV at 12 weeks. Seven treatmentexperienced patients with genotype $1 \mathrm{~b}$ received daclatasvir plus asunaprevir for 24 weeks. SVR12 rate was $85.7 \%$ (6/7). One patient experienced viral breakthrough with RAV (L31M, $\mathrm{Y} 93 \mathrm{H}$ ) at 12 weeks. Four patients with genotype $2 \mathrm{a} / 2 \mathrm{~b}$ received sofosbuvir plus ribavirin for 12 weeks. SVR12 rate was $100 \%$ (4/4). No serious adverse event-related discontinuations were noted. Conclusions: New direct acting antiviral treatment achieved high SVRs rates at 12 weeks in $\mathrm{CHC}$ patients with hemophilia without serious adverse events. (Gut Liver 2017;11:721-727)

Key Words: Hepatitis C, chronic; Sofosbuvir; Ledipasvir; Daclatasvir; Asunaprevir

\section{INTRODUCTION}

Hepatitis C virus (HCV) was discovered in 1989. According to the Korea Hemophilia Foundation registry database, the preva- lence of anti-HCV positivity in patients with hemophilia was $37.3 \%(496 / 1,329)$ in 1999 . By 2015, its prevalence was gradually reduced to $26.7 \%(550 / 2,063) .{ }^{1}$ Especially, the prevalence of hepatitis C (HCV RNA positive) in patients with hemophilia decreased strikingly from $13.5 \%$ to $1.8 \%$ between the 1990 s and 2015. ${ }^{1}$ Modern treatments of hemophilia promise a remarkable increase of the life expectancy of patients. Therefore, the quality of life of hemophilia patients with comorbidity is a major issue. Among comorbidities, HCV infection is important in patients with hemophilia. Our previous study showed that pegylated interferon (Peg-IFN) plus ribavirin (RBV) therapy in chronic hepatitis $\mathrm{C}(\mathrm{CHC})$ patients with hemophilia appeared to be superior to those without hemophilia, and there were no serious adverse events related to hemophilia. ${ }^{2}$

However, compliance with treatment is poor due to frequent side effects and the need for frequent subcutaneous injection. In $\mathrm{CHC}$ patients with hemophilia, the most common adverse events were hair loss, headache, itching, neutropenia, fatigue, and anemia. These are all related to subsequent therapeutic failure. However, with the development and launch of new direct acting antiviral agents (DAAs), it is now possible to eradicate $\mathrm{HCV}$ with a higher cure rate and significantly reduced adverse events. Most physicians are saying that we have reached an era of cure. ${ }^{3}$ However, there are a few reports regarding treatment outcomes of new DAAs in CHC patients with hemophilia. ${ }^{4}$

Therefore, in this study, we assessed the efficacy and safety of new DAA in CHC patients with hemophilia who are either treatment-naïve or treatment-experienced.

\section{MATERIALS AND METHODS}

\section{Study population}

A total of 30 patients with hemophilia and $\mathrm{CHC}$ visited the

Correspondence to: Hyung Joon Kim

Department of Internal Medicine, Chung-Ang University College of Medicine, 102 Heukseok-ro, Dongjak-gu, Seoul 06973, Korea

Tel: +82-2-6299-1417, Fax: +82-2-6299-1137, E-mail: mdjoon@cau.ac.kr

Received on May 9, 2017. Revised on June 24, 2017. Accepted on June 24, 2017.

pISSN 1976-2283 eISSN 2005-1212 https://doi.org/10.5009/gnl17209

() This is an Open Access article distributed under the terms of the Creative Commons Attribution Non-Commercial License (http://creativecommons.org/licenses/by-nc/4.0) which permits unrestricted non-commercial use, distribution, and reproduction in any medium, provided the original work is properly cited. 
Korea Hemophilia Foundation Hospital between September 2015 and April 2016. All were followed for at least 6 months after new DAAs treatment and enrollment in the current study. Patients enrolled in this study met the following entry criteria: 20 to 75 years of age and positive for serum anti-HCV for at least 6 months with HCV RNA $\geq 10^{4} \mathrm{IU} / \mathrm{mL}$; Additional requirements included a hemoglobin value $\geq 10 \mathrm{~g} / \mathrm{dL}$, a platelet count $\geq 100,000 \mathrm{~mm}^{3}$, and normal renal function with normal serum creatinine level. Candidates were required to have compensated liver disease with a prolonged prothrombin time less than 4 seconds, a serum albumin $\geq 3.0 \mathrm{~g} / \mathrm{dL}$, a total bilirubin $\leq 4 \mathrm{mg} / \mathrm{dL}$, and no history of hepatic encephalopathy or bleeding esophageal varices. Cirrhosis was diagnosed with radiological evidence of liver coarseness, nodularity, and splenomegaly $(>13 \mathrm{~cm}$ ) using ultrasonography, because liver biopsy confirmation is not available in patients with hemophilia.

Other exclusion criteria were as follows: a history of corticosteroid treatment within 6 months of entry; the presence of antigen to hepatitis B virus, or the presence of antibody to hepatitis D virus; a history of other malignancy except hepatocellular carcinoma (HCC) or evidence of other forms of liver disease; and a history of intravenous drug abuse. Patients with other significant medical or psychiatric problems were also excluded.

Twenty-six patients were genotype $1(1 \mathrm{~b}, \mathrm{n}=21 ; 1 \mathrm{a}, \mathrm{n}=5)$, and four patients were genotype $2 \mathrm{a} / 2 \mathrm{~b}$. Among the 21 patients with genotype $1 \mathrm{~b}$, Y93H resistance-associated variants (RAVs) were detected in three patients (14.3\%). According to the medical insurance system in Korea, five patients with genotype 1a and three patients with genotype $1 \mathrm{~b}$ (RAV positive) were treatmentnaïve and received ledipasvir/sofosbuvir (LDV/SOF). LDV (90 $\mathrm{mg}$ )/SOF (400 mg) was administered orally once daily for 12 weeks. Eighteen patients with genotype $1 \mathrm{~b}$ were treatmentnaïve $(n=11)$ or treatment-experienced $(n=7)$ and received daclatasvir plus asunaprevir (DCV and ASV). DCV (60 mg) was administered orally once daily and ASV (100 mg) was administered orally twice daily for 24 weeks. Four patients with genotype $2 \mathrm{a} / 2 \mathrm{~b}$ (treatment-naïve, $\mathrm{n}=2$; treatment-experienced, $\mathrm{n}=2$ ) received sofosbuvir plus ribavirin (SOF and RBV). They received 12 weeks of treatment with once daily SOF $400 \mathrm{mg}$ plus twice daily, weight-based RBV (1,000 mg or 1,200 mg) (Fig. 1).

The study protocol conformed to the ethical guidelines of the 1975 Declaration of Helsinki and was approved by the Institutional Review Board of Chung-Ang University College of Medicine, and written informed consent was obtained from each patient (IRB number: 1701-010-261).

\section{Endpoints and definitions}

The primary end point of this study was achievement of sustained virologic responses (SVRs), defined as undetectable HCV RNA in serum at 12 weeks after completion of antiviral therapy. Secondary end points were rapid virologic responses (RVRs; seronegativity of HCV RNA at 4 weeks of treatment), end-oftreatment responses (ETRs; seronegativity of HCV RNA at the end of 12 or 24 weeks of treatment), nonresponse (less than $2 \log _{10}$ decrease in HCV RNA from baseline during treatment period), and relapse (HCV RNA undetectable during antiviral therapy but detectable at 12 weeks after the end of treatment). In addition, the safety of new DAAs was assessed by clinical adverse events and laboratory abnormalities during the followup period.

\section{Assay methodology}

HCV genotyping was performed using the restriction fragment mass polymorphism method. Serum HCV RNA quantification was determined with the Cobas Amplicor HCV Monitor, v2.0 (Roche Diagnostics, Branchburg, NJ, USA), which has a lower limit of quantification of $15 \mathrm{IU} / \mathrm{mL}$. Plasma samples for determination of HCV viral titer were collected before the start of antiviral treatment, at 4 weeks after treatment, at the end of treatment (12 weeks after LDV and SOF treatment, 24 weeks after DCV and ASV in genotype $1 \mathrm{~b}$ and 12 weeks after SOF and RBV treatment in genotype $2 \mathrm{a} / 2 \mathrm{~b}$ ), and at 12 weeks after cessation of treatment. Alanine aminotransferase, was evaluated at every visit.
Week

Genotype 1b

Resistance associated variants (RAVs) -

Treatment-naïve $(n=11) /$ experienced $(n=7)$

Genotype 1b

Resistance associated variants (RAVs)+

Treatment-naïve $(n=3)$

Genotype 1a

Treatment-naïve $(n=5)$

Genotype 2a/2b

Treatment-naïve $(n=2) /$ experienced $(n=2)$
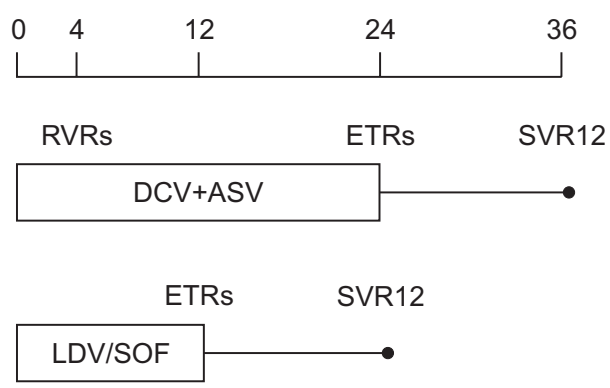

LDV/SOF

SOF+RBV
Fig. 1. Patient disposition. RAVs, resistance-associated variants; RVRs, rapid virologic responses; ETRs, end-of-treatment responses; SVR12, sustained virologic responses at 12 weeks; DCV, daclatasvir; ASV, asunaprevir; LDV/SOF, ledipasvir/ sofosbuvir; SOF, sofosbuvir; RBV, ribavirin. 
The viral resistance testing on NS5A was performed on baseline samples for all patients and samples at the first time of virologic failure in patients with viral breakthrough by direct sequencing method. Viral RNA was extracted from serum using QIAamp Viral RNA Mini Kits (QIAGEN, Hilden, Germany). The extracted RNA was reverse transcribed and amplified by the PCR method using the SuperScript III One-Step RT-PCR System with Platinum Taq DNA Polymerase (Invitrogen, San Diego, CA, USA) with the pairs of primers as follows: sense (5872-5891) 5'AAGAGGCTCCACCAGTGGAT-3' and antisense (6730-6749) 5'-CGCCGGAGCGTACCTGTGCA-3'. The targeted HCV genome was amplified by nested PCR using PrimeSTAR Max DNA Polymerase (TaKaRa), with the pairs of primers as follows: sense (5893-5912) 5'-AATGAGGACT GCTCCACGCC-3' and antisense (6690-6709) 5'-GTG AAGAATTCGGGGGCCGG-3'. The PCR products were purified using a QIAquick PCR Purification Kit (QIAGEN) and sequenced using an automated DNA sequencer (3730xl DNA Analyzer; Applied Biosystems, Foster City, CA, USA). Substitution at amino acid positions 31 (L31F/ $\mathrm{I} / \mathrm{M} / \mathrm{V}$ ), and 93 (Y93H) known to be associated with resistanceassociated GT-1 virologic failures on DCV were analyzed. ${ }^{5}$ If minor sequences of RAVs were detected in more than 10\% of the strength of the major sequence, it was regarded as RAVs positive. For analysis, the predicted HCV amino acid sequences from the patients were compared with the sequence of the HCVJ strain (GenBank accession number: AJ238799, http://www.
ncbi.nlm.nih.gov/nuccore/AJ238799.1) as a reference.

\section{Statistical analysis}

All data are expressed as mean \pm standard deviation or range where appropriate. HCV RNA levels were logarithmically transformed for analysis. Continuous variables are presented as mean with standard deviation, whereas qualitative and discrete variables are expressed as absolute number and relative proportion in percentage.

\section{RESULTS}

\section{Study population}

In total, 30 patients with hemophilia and $\mathrm{CHC}$ were enrolled and treated at the Korea Hemophilia Foundation Hospital between September 2015 and April 2016. The characteristics at baseline are shown in Table 1; 30 patients (100\%) were male, and the mean age was 46 years (range, 30 to 75 years). Four patients (13.3\%) had compensated liver cirrhosis. The mean baseline serum ALT level was $66 \mathrm{IU} / \mathrm{L}$ (range, 16 to $207 \mathrm{IU} / \mathrm{L}$ ), and the mean baseline serum HCV RNA level was $6.3 \log _{10}$ copies $/ \mathrm{mL}$ (range, 4.2 to $7.1 \log _{10}$ copies $/ \mathrm{mL}$ ). The mean baseline BMI was $23.6 \mathrm{~kg} / \mathrm{m}^{2}$ (range, 16.9 to $41.6 \mathrm{~kg} / \mathrm{m}^{2}$ ). Overall, $50 \%$ of patients were treatment-experienced patients. The mean total follow-up period was 36 weeks (range, 18 to 78 weeks) (Table 1).

Table 1. Clinical Characteristics of 30 Patients with Chronic Hepatitis C and Hemophilia

\begin{tabular}{|c|c|c|c|c|}
\hline \multirow{3}{*}{ Characteristic } & \multicolumn{2}{|c|}{ HCV genotype $1 b$} & \multirow{2}{*}{ HCV genotype 1a } & \multirow{2}{*}{ HCV genotype $2 a / 2 b$} \\
\hline & RAV (-) & RAV (+) Y93H & & \\
\hline & DCV and ASV $(n=18)$ & LDV/SOF $(n=3)$ & LDV/SOF $(n=5)$ & SOF and RBV $(n=4)$ \\
\hline Age, yr & $45(32-75)$ & $53(44-61)$ & $42(30-53)$ & $53(44-63)$ \\
\hline Male sex & $18(100)$ & $3(100)$ & $5(100)$ & $4(100)$ \\
\hline BMI, $\mathrm{kg} / \mathrm{m}^{2}$ & $23.1(19.1-31.0)$ & $27.0(21.8-31.6)$ & $26.0(18.7-41.6)$ & $20.3(16.9-23.4)$ \\
\hline HCV RNA, $\log _{10} I U / m L$ & $6.2(5.4-6.8)$ & $6.4(6.1-6.7)$ & $6.9(6.5-7.1)$ & $5.9(4.2-7.0)$ \\
\hline \multicolumn{5}{|l|}{ Prior HCV treatment } \\
\hline Treatment-naïve & $11(61.1)$ & 1 (33.3) & $2(40.0)$ & $2(50.0)$ \\
\hline Relapse & $5(27.8)$ & $2(66.7)$ & - & - \\
\hline Breakthrough & - & - & - & - \\
\hline Intolerance & - & - & $1(20.0)$ & $2(50.0)$ \\
\hline Nonresponse & $2(11.1)$ & - & $2(40.0)$ & - \\
\hline Cirrhosis & $2(11.1)$ & 1 (33.3) & $1(20.0)$ & 0 \\
\hline Treatment-naïve & $1(5.6)$ & - & - & - \\
\hline Relapse & - & $1(33.3)$ & - & - \\
\hline Nonresponse & $1(5.6)$ & - & $1(20.0)$ & - \\
\hline ALT, U/L & 78.1 (32-207) & $56.7(46-74)$ & $68(19-154)$ & $23.2(16-30)$ \\
\hline Hemoglobin, g/dL & $13.7(10.0-15.5)$ & $14.1(12.7-14.9)$ & $13.6(12.4-14.6)$ & $13.5(12.0-14.5)$ \\
\hline
\end{tabular}

Data are presented as mean (range) or number (\%).

HCV, hepatitis C virus; RAV, resistance-associated variant; DCV, daclatasvir; ASV, asunaprevir; LDV/SOF, ledipasvir/sofosbuvir; RBV, ribavirin; BMI, body mass index; ALT, alanine aminotransferase. 


\section{Antiviral response}

According to the medical insurance system in Korea, 11 patients with genotype $1 \mathrm{~b}$ were treatment-naïve and received DCV plus ASV for 24 weeks (Table 2). The RVRs rate was 100\% (11/11), while ETRs, and SVR12 rates were 91\% (10/11). One patient experienced viral breakthrough without RAVs at 12 weeks. Seven treatment-experienced patients with genotype $1 \mathrm{~b}$ received DCV plus ASV for 24 weeks. The RVRs rate was 100\% (7/7). However, ETRs, and SVR12 rates were 85.7\% (6/7). One patient experienced viral breakthrough with RAVs (L31M, Y93H) at 12 weeks. Baseline characteristics of patients with virologic failure are shown in Table 3. At baseline, RAVs were not detected in these patients. They also experienced virologic breakthrough regardless of the achievement of RVR. Only one patient with nonresponse in previous treatment experienced virologic breakthrough with RAVs. No patients displayed nonresponse or relapse after ETRs.
Five patients with genotype 1a and three patients with genotype $1 \mathrm{~b}$ (RAVs positive) received LDV/SOF for 12 weeks. RVRs, ETRs, and SVR12 rates were 100\% (8/8). Four patients with genotype $2 \mathrm{a} / 2 \mathrm{~b}$ (treatment-naïve, $\mathrm{n}=2$; treatment-experienced, $\mathrm{n}=2$ ) received SOF plus RBV for 12 weeks. RVRs, ETRs, and SVR12 rates were $100 \%(4 / 4)$.

Three patients with genotype $1 \mathrm{~b}$ and one patient with genotype 1a were classified as having cirrhosis. Among them, two patients experienced nonresponse and one patient experienced relapse in previous Peg-IFN plus RBV therapy (Table 1). However, all cirrhotic patients achieved SVR.

\section{Safety}

The most common adverse events were fatigue, headache, nausea, insomnia and dizziness (Table 4). Most adverse events were mild, and only a few patients experienced mild hematologic events. The proportion of patients with mild anemia (hemoglobin, 8 to $<12 \mathrm{~g} / \mathrm{dL}$ ) was $40 \%$. However, the adverse events,

Table 2. Treatment Response

\begin{tabular}{|c|c|c|c|c|c|}
\hline \multirow{4}{*}{$\begin{array}{l}\text { HCV RNA, } \\
\text { undetectable* }\end{array}$} & \multicolumn{3}{|c|}{ HCV genotype $1 b$} & \multirow{2}{*}{ HCV genotype $1 \mathrm{a}$} & \multirow{2}{*}{ HCV genotype $2 a / 2 b$} \\
\hline & \multicolumn{2}{|c|}{$\operatorname{RAV}(-)$} & RAV (+) Y93H & & \\
\hline & \multicolumn{2}{|c|}{ DCV and ASV } & $\mathrm{LDV} / \mathrm{SOF}$ & LDV/SOF & SOF and RBV \\
\hline & Naïve $(n=11)$ & Experienced $(\mathrm{n}=7)$ & $\begin{array}{l}\text { Naïve and experienced } \\
\qquad(\mathrm{n}=3)\end{array}$ & $\begin{array}{l}\text { Naïve and experienced } \\
\qquad(n=5)\end{array}$ & $\begin{array}{l}\text { Naïve and experienced } \\
\qquad(\mathrm{n}=4)\end{array}$ \\
\hline \multicolumn{6}{|l|}{ During treatment } \\
\hline Week 4 & $11(100)$ & 7 (100) & $3(100)$ & $5(100)$ & $4(100)$ \\
\hline Week12 & $10(90.9)$ & $6(85.7)$ & $3(100)$ & $5(100)$ & $4(100)$ \\
\hline Week 24 & $10(90.9)$ & $6(85.7)$ & - & - & - \\
\hline \multicolumn{6}{|l|}{ Post treatment } \\
\hline Week 4 & $10(90.9)$ & $6(85.7)$ & $3(100)$ & $5(100)$ & $4(100)$ \\
\hline Week 12 & $10(90.9)$ & 6 (85.7) & $3(100)$ & $5(100)$ & $4(100)$ \\
\hline \multicolumn{6}{|l|}{ Virologic failure } \\
\hline On treatment & $1(9.1)^{\dagger}$ & $1(14.3)^{\ddagger}$ & - & - & - \\
\hline Relapse & - & - & - & - & - \\
\hline
\end{tabular}

Data are presented as number (\%).

HCV, hepatitis C virus; RAV, resistance-associated variant; DCV, daclatasvir; ASV, asunaprevir; LDV/SOF, ledipasvir/sofosbuvir; RBV, ribavirin. *The lower limit of detection for the HCV RNA test is $15 \mathrm{IU} / \mathrm{mL}$; ${ }^{\dagger}$ This patient experienced viral breakthrough without RAV at 12 weeks; ${ }^{\ddagger}$ This patient experienced viral breakthrough with RAV (L31M, Y93H) at 12 weeks.

Table 3. Baseline Characteristics of Patients with Virologic Failure

\begin{tabular}{|c|c|c|c|c|c|c|c|c|c|c|}
\hline Patient & Drug & $\begin{array}{l}\text { Age, } \\
\text { yr }\end{array}$ & $\begin{array}{l}\text { BMI, } \\
\mathrm{kg} / \mathrm{m}^{2}\end{array}$ & Genotype & $\begin{array}{l}\text { Previous } \\
\text { treatment }\end{array}$ & $\begin{array}{l}\text { HCV RNA, } \\
\log _{10} I U / m L\end{array}$ & $\begin{array}{l}\text { ALT, } \\
\text { U/L }\end{array}$ & Cirrhosis & $\begin{array}{l}\text { Undetectable } \\
\text { HCV RNA, wk* }\end{array}$ & Response \\
\hline 1 & DCV and ASV & 38 & 26.2 & $1 \mathrm{~b}$ & Naïve & 6.4 & 32 & No & 4 & $\begin{array}{l}\text { Breakthrough } \\
\text { without RAVs }\end{array}$ \\
\hline 2 & DCV and ASV & 45 & 21.6 & $1 \mathrm{~b}$ & Nonresponse & 5.8 & 37 & No & 4 & $\begin{array}{l}\text { Breakthrough with } \\
\text { RAVs (L31M, Y93H) }\end{array}$ \\
\hline
\end{tabular}

BMI, body mass index; HCV, hepatitis C virus; ALT, alanine aminotransferase; DCV, daclatasvir; ASV, asunaprevir; RAVs, resistance-associated variants.

*The lower limit of detection for the HCV RNA test is $15 \mathrm{IU} / \mathrm{mL}$. 
Table 4. Treatment-Related Adverse Events and Laboratory Abnormalities

\begin{tabular}{|c|c|c|c|c|c|}
\hline \multirow{3}{*}{$\begin{array}{l}\text { Adverse events and laboratory } \\
\text { abnormalities }\end{array}$} & \multicolumn{2}{|c|}{ HCV genotype $1 \mathrm{~b}$} & \multirow{3}{*}{$\begin{array}{l}\text { HCV genotype 1a } \\
\text { LDV/SOF }(n=5)\end{array}$} & \multirow{3}{*}{$\begin{array}{l}\text { HCV genotype } 2 \mathrm{a} / 2 \mathrm{~b} \\
\text { SOF and RBV }(\mathrm{n}=4)\end{array}$} & \multirow{3}{*}{ Total $(n=30)$} \\
\hline & \multirow{2}{*}{$\begin{array}{c}\text { RAV }(-) \\
\text { DCV and ASV }(n=18)\end{array}$} & \multirow{2}{*}{$\begin{array}{l}\text { RAV (+) Y93H } \\
\text { LDV/SOF }(n=3)\end{array}$} & & & \\
\hline & & & & & \\
\hline Patients with SAE & 0 & 0 & 0 & 0 & 0 \\
\hline Discontinued due to $\mathrm{AE}$ & 0 & 0 & 0 & 0 & 0 \\
\hline \multicolumn{6}{|l|}{ Patients with any $\mathrm{AE}$} \\
\hline Headache & $3(16.7)$ & $1(33.3)$ & $2(40.0)$ & $2(50.0)$ & $8(26.7)$ \\
\hline Fatigue & $6(33.3)$ & $1(33.3)$ & $1(20.0)$ & $2(50.0)$ & $10(33.3)$ \\
\hline Nausea & $2(11.1)$ & 0 & $2(40.0)$ & $2(50.0)$ & $6(20.0)$ \\
\hline Insomnia & $2(11.1)$ & $1(33.3)$ & 0 & $2(50.0)$ & $5(16.7)$ \\
\hline Itching & 0 & $1(33.3)$ & 0 & 0 & $1(3.3)$ \\
\hline Rash & 0 & 0 & 0 & 0 & 0 \\
\hline Diarrhea & $2(11.1)$ & 0 & 0 & 0 & $2(6.7)$ \\
\hline Anxiety & 0 & 0 & 0 & $1(25.0)$ & $1(3.3)$ \\
\hline Dizziness & $2(11.1)$ & 0 & $1(20.0)$ & $2(50.0)$ & $5(16.7)$ \\
\hline \multicolumn{6}{|l|}{ Laboratory abnormalities } \\
\hline Hemoglobin ( 10 to $<12 \mathrm{~g} / \mathrm{dL})$ & $4(22.2)$ & 0 & $2(40.0)$ & $2(50.0)$ & $8(26.7)$ \\
\hline Hemoglobin $(8$ to $<10 \mathrm{~g} / \mathrm{dL})$ & $2(11.1)$ & 0 & 0 & $2(50.0)$ & $4(13.3)$ \\
\hline Total bilirubin ( $>1.0$ to $2.5 \times \mathrm{ULN})$ & 0 & 0 & 0 & $1(25.0)$ & $1(3.3)$ \\
\hline Total bilirubin ( $>2.5$ to $5.0 \times \mathrm{ULN})$ & 0 & 0 & 0 & $1(25.0)$ & $1(3.3)$ \\
\hline $\operatorname{ALT}(>5.0$ to $10 \times \mathrm{ULN})$ & $2(11.1)$ & 0 & 0 & 0 & $2(6.7)$ \\
\hline Neutrophil ( 800 to $<1,000 \times \mathrm{mm}^{3}$ ) & $1(5.6)$ & 0 & 0 & 0 & $1(3.3)$ \\
\hline
\end{tabular}

Data are presented as number (\%).

HCV, hepatitis C virus; RAV, resistance-associated variant; DCV, daclatasvir; ASV, asunaprevir; LDV/SOF, ledipasvir/sofosbuvir; RBV, ribavirin; SAE, serious adverse event; AE, adverse event; ULN, upper limit of normal; ALT, alanine aminotransferase.

spontaneous hemarthrosis, and obscure gastrointestinal bleeding, were not considered treatment-related but rather to have originated from hemophilia. Moreover, no patients experienced major bleeding. Adherence to new DAAs including RBV was reported to be $100 \%$. There was no patient who discontinued the treatment or reduced the dosage due to a serious adverse event (Table 4). No patients underwent RBV dose reduction due to anemia. The adverse events reported in $\mathrm{CHC}$ patients with hemophilia were consistent with CHC patients without hemophilia reported in previous studies, except development of anemia.

\section{DISCUSSION}

Although the prevalence of $\mathrm{CHC}$ in patients with hemophilia has gradually decreased, these patients have one of the highest prevalence rates of $\mathrm{CHC}$ among the general population. ${ }^{6}$ Before HCV-specific screening was established, more than $80 \%$ of patients with hemophilia experienced $\mathrm{CHC}$ and about 20\% had progressed to liver cirrhosis and HCC within 30 years. Between 1990 and 2007, complications of HCV were the leading cause of mortality in individuals with hemophilia. ${ }^{7}$ The host factors of long duration disease and male sex have a strong associa- tion with reduced antiviral responsiveness and fibrosis progression, respectively. ${ }^{8,9}$ In other words, the mean age of infection is lower than that of the general population at risk for HCV because almost all patients with hemophilia were treated with plasma products from childhood before 1987. A long duration of infection also increases the risk of advanced liver disease and liver-related mortality. Therefore, active and intensive treatment of HCV is required to prevent the progression of liver disease in patients with hemophilia.

For several years, the current standard of care for the treatment of CHC was Peg-IFN and RBV combination therapy. A meta-analysis of antiviral therapy in CHC patients with hemophilia demonstrated that the overall SVRs rate to Peg-IFN and RBV was 61\% (45\% for genotype 1 and 79\% for non-1 genotype). ${ }^{10,11}$ While the efficacy of this therapy was acceptable, about 40\% of patients with CHC experienced breakthrough or relapse, especially genotype 1 patients. Although the SVRs rate was about $85 \%$ (82\% in genotype 1, 92\% in genotype 2 or 3 ) in our previous Korean hemophilia data, higher than that in the meta-analysis, there have been still many requests to increase the SVRs. ${ }^{2}$

Female sex tends to correlate with SVRs, but patients with 
hemophilia are exclusively male. In addition, in our previous Korean hemophilia study, about $8 \%$ of patients discontinued treatment due to serious adverse events such as anemia, general weakness, jaundice, and periodontitis. ${ }^{2}$ These side effects are especially the main drawback of Peg-IFN and RBV in patients with blood disorders. Unfortunately, most CHC patients with hemophilia hesitate to use Peg-IFN and RBV because of their side effects.

Recently, the development and approval of new DAAs have revolutionized treatment in patients with $\mathrm{CHC}^{12-14}$ It is now possible to eradicate HCV with a higher cure rate and to significantly reduce adverse events and shorten the time for treatment. Especially, SOF is a very important antiviral agent with unique safety and excellent efficacy. ${ }^{15}$ Overall, more than 90\% of patients achieved SVRs with 12 weeks of LDV/SOF in the ION-1, ION-2, and ION-3 study. ${ }^{16-19}$ In our current results, SVRs rates following LDV/SOF treatment showed an excellent result (100\%) with few side effects in CHC genotype $1 \mathrm{a} / 1 \mathrm{~b}$ patients with hemophilia. In addition, SVRs rates after SOF-based therapy also showed complete results (100\%) regardless of genotype.

In genotype $2 \mathrm{a} / 2 \mathrm{~b}$, more than 90\% achieved SVRs with 12 weeks of SOF and RBV in the FISSION and POSITRON studies. ${ }^{20,21}$ Our results also demonstrated that SOF and RBV therapy showed complete SVRs (100\%) in genotype 2a/2b. Although all four patients with genotype $2 \mathrm{a} / 2 \mathrm{~b}$ experienced anemia (hemoglobin, 8 to $<12 \mathrm{~g} / \mathrm{dL}$ ), neither discontinuation nor dose reduction of RBV were noted because of anemia.

Systematic review and meta-analysis suggest that Peg-IFNfree DCV and ASV provides an effective and tolerable therapeutic option for treatment-naïve and treatment-experienced patients with HCV genotype $1 \mathrm{~b}$, irrespectively of cirrhosis. ${ }^{22}$ This systematic review analyzed nine studies with 1,690 patients who have HCV genotype 1b infection. The rate of SVR was significantly higher in treatment-naïve group (89.9\%) than in treatment experienced group (80.6\%). ${ }^{22}$ Moreover, high SVR rates were obtained irrespective of baseline cirrhosis status. These results are similar to our results from Korean hemophiliacs with HCV genotype 1b (90.0\%, 85.7\%). Although two hemophiliacs with cirrhosis were treated with DCV and ASV, they all achieved SVR. A subanalysis in Asian patients from HALLMARK DUAL study, including Korean, Japanese, and Taiwanese patients, showed high treatment adherence $(96.1 \%$ of planned treatment adherence), increased SVR rates (83.7\%) after DCV plus ASV treatment together with few adverse events in patients with genotype $1 .^{23}$ The SVR rates were $92.3 \%$ and $79.2 \%$ in treatment-naïve and treatment experienced, respectively.

However, about 10\% of Asian patients experienced treatment-emergent RAVs and viral breakthrough in spite of no RAVs (L31M/V and/or Y93H) at baseline. ${ }^{23}$ In our study, two patients (11.1\%) also experienced on treatment virologic failure in spite of RVRs. One treatment-naïve patient with genotype $1 \mathrm{~b}$ experienced viral breakthrough without RAVs at 12 weeks; this patient's compliance was good, and the repeated RAVs test after 4 weeks was also negative. The other treatment-experienced patient with genotype $1 \mathrm{~b}$ experienced viral breakthrough with RAVs (L31M, Y93H) at 12 weeks. Interestingly, this patient was nonresponsive to previous Peg-IFN and RBV treatment. Our results suggest that the Korean health insurance system could be changed from DCV and ASV to LDV/SOF in patients with CHC genotype $1 \mathrm{~b}$ hemophilia, with or without RAV.

Our study did have a few limitations. This study was based on a retrospective, nonrandomized design and only included Korean patients with hemophilia. In a previous report from 2012, 118 patients (6.3\%) had positive HCV RNA among 1,862 patients with hemophilia. ${ }^{1}$ It was difficult to enroll patients in our study because some patients had already received treatment with Peg-IFN and RBV between 2012 and 2014, thus they were not eligible for the current study.

In conclusion, IFN-free DAAs had high antiviral efficacy in patients with HCV, even in patients with hemophilia, and the safety profile and tolerability were similar to those in patients without hemophilia. As expected, the incidence of anemia was slightly higher among patients receiving SOF and RBV than among patients receiving LDV/SOF or DCV and ASV. Our data suggest that physicians should treat $\mathrm{CHC}$ patients with hemophilia using DAAs early and actively to prevent disease progression.

\section{CONFLICTS OF INTEREST}

No potential conflict of interest relevant to this article was reported.

\section{ACKNOWLEDGEMENTS}

H.W.L. analyzed the clinical data, and wrote the paper; K.Y.Y. and J.W.W. provided clinical data and performed research; H.J.K. edited and reviewed the manuscript.

\section{REFERENCES}

1. Kim DH, Kim SK, Park SK, Yoo KY, Hwang TJ, Choi YM. Korea hemophilia foundation registry trends 1991-2012: patient registry, demographics, health services utilization. Haemophilia 2015;21:e479-e480.

2. Yang SY, Lee HW, Lee YJ, Park SJ, Yoo KY, Kim HJ. Highly effective peginterferon alpha-2a plus ribavirin combination therapy for chronic hepatitis C in hemophilia in Korea. Clin Mol Hepatol 2015;21:125-130.

3. Lee HW. Nonzero risk of hepatocellular carcinoma even after sustained virological response. Gut Liver 2016;10:661-662.

4. Walsh CE, Workowski K, Terrault NA, et al. Ledipasvir-sofosbuvir and sofosbuvir plus ribavirin in patients with chronic hepatitis C and bleeding disorders. Haemophilia 2017;23:198-206. 
5. McPhee F, Suzuki Y, Toyota J, et al. High sustained virologic response to daclatasvir plus asunaprevir in elderly and cirrhotic patients with hepatitis $\mathrm{C}$ virus genotype $1 \mathrm{~b}$ without baseline NS5A polymorphisms. Adv Ther 2015;32:637-649.

6. Posthouwer D, Makris M, Yee TT, et al. Progression to end-stage liver disease in patients with inherited bleeding disorders and hepatitis C: an international, multicenter cohort study. Blood 2007;109:3667-3671.

7. Tagliaferri A, Rivolta GF, Iorio A, et al. Mortality and causes of death in Italian persons with haemophilia, 1990-2007. Haemophilia 2010;16:437-446.

8. Poynard T, Bedossa P, Opolon P. Natural history of liver fibrosis progression in patients with chronic hepatitis C: the OBSVIRC, METAVIR, CLINIVIR, and DOSVIRC groups. Lancet 1997;349:825832.

9. Fried MW, Peter J, Hoots K, et al. Hepatitis C in adults and adolescents with hemophilia: a randomized, controlled trial of interferon alfa-2b and ribavirin. Hepatology 2002;36(4 Pt 1):967-972.

10. Franchini M, Mengoli C, Veneri D, Mazzi R, Lippi G, Cruciani M. Treatment of chronic hepatitis $\mathrm{C}$ in haemophilic patients with interferon and ribavirin: a meta-analysis. J Antimicrob Chemother 2008;61:1191-1200.

11. Wilde JT, Mutimer D, Dolan G, et al. UKHCDO guidelines on the management of HCV in patients with hereditary bleeding disorders 2011. Haemophilia 2011;17:e877-e883.

12. Korean Association for the Study of the Liver. KASL clinical practice guidelines: management of hepatitis C. Clin Mol Hepatol 2016;22:76-139.

13. European Association for the Study of the Liver. EASL recommendations on treatment of hepatitis C 2016. J Hepatol 2017;66:153194.

14. AASLD/IDSA HCV guidance panel. Hepatitis C guidance: AASLD-
IDSA recommendations for testing, managing, and treating adults infected with hepatitis C virus. Hepatology 2015;62:932-954.

15. McQuaid T, Savini C, Seyedkazemi S. Sofosbuvir, a significant paradigm change in HCV treatment. J Clin Transl Hepatol 2015;3:27-35.

16. Jensen CM, Holle LM. Ledipasvir-sofosbuvir: a once-daily oral treatment option for chronic hepatitis $\mathrm{C}$ virus genotype 1 infection. Pharmacotherapy 2016;36:562-574.

17. Afdhal N, Zeuzem S, Kwo P, et al. Ledipasvir and sofosbuvir for untreated HCV genotype 1 infection. N Engl J Med 2014;370:1889-1898.

18. Afdhal N, Reddy KR, Nelson DR, et al. Ledipasvir and sofosbuvir for previously treated HCV genotype 1 infection. N Engl J Med 2014;370:1483-1493.

19. Kowdley KV, Gordon SC, Reddy KR, et al. Ledipasvir and sofosbuvir for 8 or 12 weeks for chronic HCV without cirrhosis. N Engl J Med 2014;370:1879-1888.

20. Lawitz E, Mangia A, Wyles D, et al. Sofosbuvir for previously untreated chronic hepatitis C infection. N Engl J Med 2013;368:18781887.

21. Jacobson IM, Gordon SC, Kowdley KV, et al. Sofosbuvir for hepatitis C genotype 2 or 3 in patients without treatment options. N Engl J Med 2013;368:1867-1877.

22. Wang HL, Lu X, Yang X, Xu N. Effectiveness and safety of daclatasvir plus asunaprevir for hepatitis $C$ virus genotype $1 \mathrm{~b}$ : systematic review and meta-analysis. J Gastroenterol Hepatol 2017;32:45-52.

23. Kao JH, Lee YJ, Heo J, et al. All-oral daclatasvir plus asunaprevir for chronic hepatitis $\mathrm{C}$ virus (HCV) genotype $1 \mathrm{~b}$ infection: a subanalysis in Asian patients from the HALLMARK DUAL study. Liver Int 2016;36:1433-1441. 